\title{
Pneumosinus Dilatans
}

\author{
Col H Singh*, Lt Col N Ramakrishnan ${ }^{+}$, Sarin ${ }^{\#}$
}

MJAFI 2007; 63 : 300-301

Key Words : Pneumosinus dilatans

\section{Introduction}

$\mathrm{P}$ neumosinus dilatans (PSD) is an idiopathic expansion of paranasal sinuses containing air without an associated mass. This rare disorder may affect all paranasal sinuses but frontal sinus involvement is common. We report a case of pneumosinus dilatans involving the frontal sinuses.

\section{Case Report}

A 27 year old serving soldier presented with gradual onset of swelling on left side of forehead above the left eyebrow along with dull intermittent pain for the past two years. Swelling was progressively increasing in size. He had no ocular and nasal complaints. Clinical examination was normal except for slight deviation of septum to right with hypertrophy of inferior turbinate on both sides. Local examination of the swelling, revealed a bony hard swelling on left side of forehead approximately $3 \times 5 \mathrm{~cm}$ in dimension (Fig. 1). The overlying skin was normal. No tenderness was elicited. On investigation, his haematological and biochemical tests including levels of growth hormone and serum alkaline phosphatase were normal. Lateral view radiograph of skull showed bulging of the anterior table without any evidence of bone erosion.

Diagnostic nasal endoscopy did not reveal any intranasal abnormality. Computed tomography (CT) scan of nose/ paranasal sinuses coronal/axial views showed extensive pneumatisation and expansion of the frontal sinus, which extended from one side of skull to the other end (Fig. 2). Axial views showed expansion of frontal sinus where anterior table of frontal sinus was pushed forward without any bony erosion. Ophthalmological assessment was normal. The diagnosis of pneumosinus dilatans (PSD) was entertained and an osteoplastic flap procedure, to correct the frontal deformity was done.

Bicoronal incision was given over the scalp and subgaleal scalp flap was raised. After raising an inferiorly based pericranial flap, the osteoplastic flap overlying the frontal sinus was elevated using a Stryker saw. Mucosa of the frontal sinus was found to be normal (Fig. 3). Anterior table of the frontal sinus was refashioned. Margins of the frontal sinus were smoothened. Osteoplastic flap reposited back and the gap over the margin of the sinus was filled with bovine bone graft. Wound was closed in layers. Suture removal was done on tenth post operative day. Postoperatively no residual deformity could be seen.

\section{Discussion}

PSD is a rare entity, first described by Benjamins [1]. It is characterised by idiopathic progressive expansion of one or more paranasal sinuses (PNS) beyond normal margins without evidence of mucous membrane changes. The expansion may involve complete or a part of the sinus [2].

The patient usually complains of slowly changing facial contours and dull pain in the affected area, diplopia or other local pressure symptoms. It should be differentiated from hyperpneumatised sinus (hypersinus) and pneumocele [3]. The aetiology and pathogenesis of PSD remains unclear. In normal subjects, there is variation in the degree of pneumatisation of the sinuses. Overgrowth may occur in an acromegalic subjects under the influence of general growth factor or as a compensatory phenomenon in cases of agenesis of a cerebral hemisphere [4]. It has been found to be associated with orbital fibro-osseous diseases [5] and intra cranial meningioma involving the frontal lobe [6]. Several mechanisms have been suggested including the most accepted ball valve mechanism at the level of the sinus ostia leading to the sinus expansion. Congenital abnormality has been proposed as a possible mechanism leading to unchecked development and growth of the sinus cavity and the meningeal cells thus leading to the PSD and associated tumours [7].

PSD is diagnosed with standard radiography, CT scan or magnetic resonance imaging (MRI) study. The diagnostic criteria includes enlargement of an air cell or the whole sinus and presence of only air in the walls of sinus.

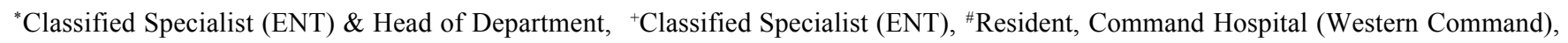
Chandimandir -134107.

Received : 22.04.2006; Accepted : 19.10.2006 


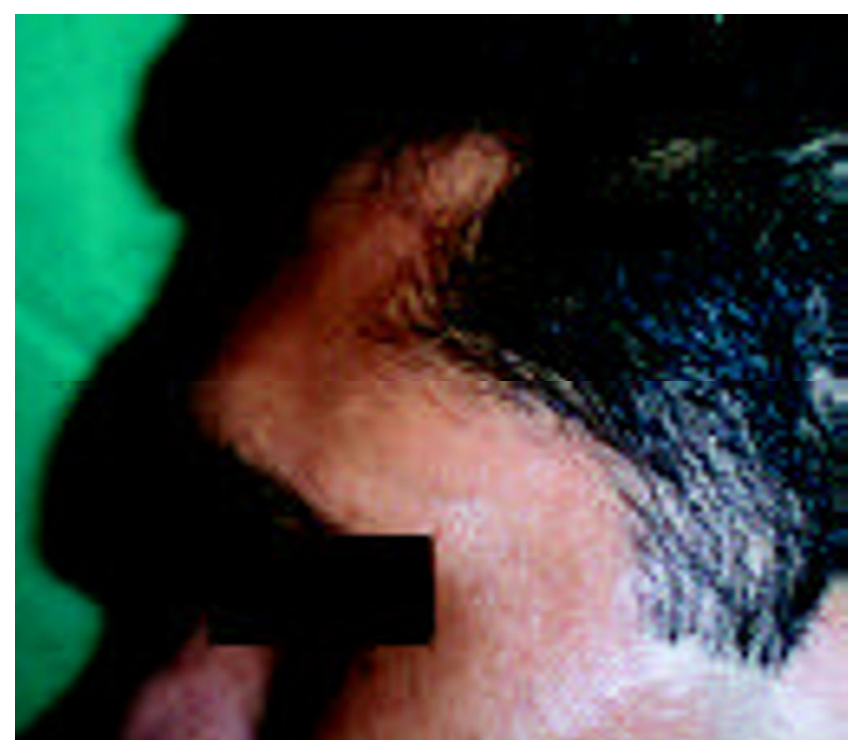

Fig.1 : Shows a bony hard swelling on left side of forehead

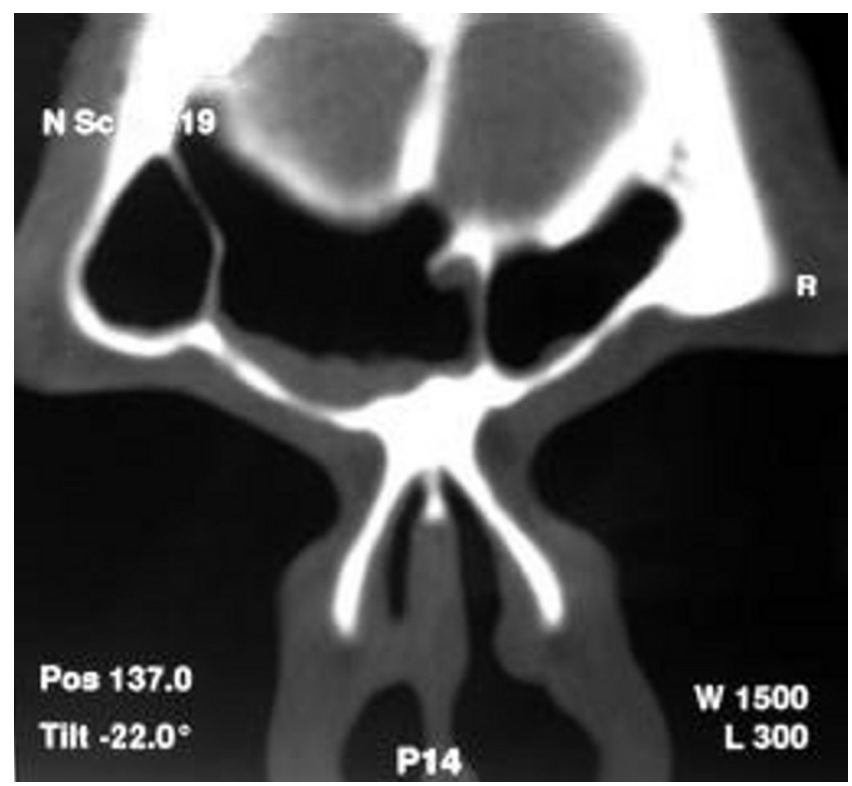

Fig.2: CT scan of paranasal sinuses showing extensive pneumatisation and expansion of the frontal sinus extending from one side of skull to the other end

Although, it is a benign condition, numerous methods of repair of the cosmetic defect have been described. Appelt et al [8], described a bicoronal approach in which the deformed anterior frontal sinus wall was reconstructed with a split calvarial bone graft harvested from the inner table of the frontal cranial bone flap. Pospisil et al [9], outlined removal of anterior wall of

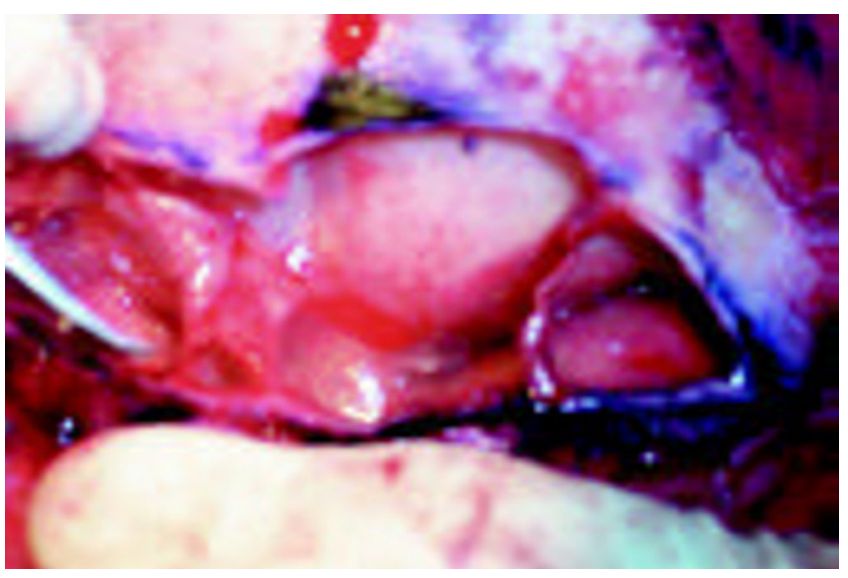

Fig.3 : Interior of the frontal sinus showing normal mucosa

the frontal sinus followed by slicing off the anterior portion of the removed anterior wall bone and rewiring the bone in place. This case is being presented due to the rarity of the condition.

\section{Conflicts of Interest}

None identified

\section{References}

1. Benjamins LE. Pneumosinus frontalis dilatans. Acta Otolaryngol 1918;1: 412-3.

2. Walkeec JL, Jones NS. Pneumosinus dilatans of the frontal sinuses: Two cases and a discussion of its aetiology. J Laryngol Otol 2002; 116:382-5.

3. Tohoku J. Pneumocele vs Pneumosinus dilatans: Review of the Literature with a case of Frontal Sinus Pneumocele.Exp Med 2002; 295-7.

4. Adams WM, Jones RI, Chavda SI, Pathor AL, Taifa KT. Pneumosinus dilatans: a discussion of four cases and the possible aetiology. Rhinology 1998; 36:40-2.

5. Dhillon RS, Williams DC. Pneumosinus dilatans. J Laryngol Otol 1987;101:828-32.

6. Miller NR, Golnik KC, Zeidman SM, North RB. Pneumosinus dilatans: a sign of intracranial meningioma. Surg Neurol 1996; 46:471-4.

7. Som PS, Edelstein D, Urken ML, Lawson W, Weber AL, Biller HF. Abnormally large frontal sinus II. Nomenclature, pathology and symptoms. Laryngoscope1987; 97:606-11.

8. Appelt EA, Wilhelmi BJ, Warder DE, Blackwell SJ. A rare case of pneumosinus dilatans of the frontal sinus and review of the literature. Ann Plast Surg 1999; 43:653-6.

9. Pospisil OA, Balmer MC. Pneumosinus dilatans. Br J Oral Maxillofac Surg 1998; 26:375-80. 